\title{
Synergistic effect of thymoquinone and nystatin in the treatment of oral candidiasis; an in vitro study
}

\author{
Özge Özdal Zincirr ${ }^{1}$ (1) $\cdot$ Umut Özdal $^{2} \cdot$ Özge Ünlü ${ }^{3} \cdot$ Mehmet Demirci $^{4} \cdot$ Ahmet Bülent Katiboğlu $^{5} \cdot$ Edibe Egil $^{6}$. \\ Gülay Altan Şallı
}

Received: 30 October 2020 / Accepted: 7 October 2021 / Published online: 17 October 2021

(c) The Society of The Nippon Dental University 2021, corrected publication 2021

\begin{abstract}
The effectiveness of antifungal agents may be insufficient against resistant strains in some cases of oral candidiasis. The aim of this study was to evaluate the antifungal effect of thymoquinone against Candida albicans, Candida tropicalis, Candida glabrata and Candida krusei strains and the synergistic antifungal activity of these strains in combination with nystatin. To evaluate in vitro antifungal activity and interactions between thymoquinone and nystatin, substances were tested against Candida albicans ATCC 10,231, C. tropicalis ATCC 750, C.krusei ATCC 6258 and C. glabrata ATCC 2001 standard strains both individually and combinationally via microdilution method. MIC and $\Sigma$ FIC index value were analysed. The Kruskal Wallis test and Bonferroni test were used for statistical evaluations. Statistical significance was set at $p<0.05$. A statistically significant difference was observed between the mean ranks of all Candida species and doses of thymoquinone, nystatin, and the combination thymoquinone-nystatin $(p<0.05)$. MIC values for thymoquinone were determined as $15 \mu \mathrm{g} / \mathrm{mL}$ for C. albicans, C. tropicalis and C. krusei while it was $30 \mu \mathrm{g} / \mathrm{mL}$ for $C$. glabrata. Moreover, MIC for nystatin was found as $1.875 \mu \mathrm{g} / \mathrm{mL}$ for $C$. albicans, C. tropicalis and C. krusei, whereas it was $7.5 \mu \mathrm{g} / \mathrm{mL}$ in C. glabrata. Interaction assays and $\Sigma$ FIC index value revealed that, TQ and nystatin have a synergistic effect against to all strains. Thymoquinone was found to have antifungal activity on Candida species and synergistic effect when combined with nystatin.
\end{abstract}

Keywords Thymoquinone $\cdot$ Candida $\cdot$ Antifungal drugs $\cdot$ Synergistic effect $\cdot$ Oral candidiasis

\section{Introduction}

Özge Özdal Zincir

ozgeozdalzincir@gmail.com

1 Faculty of Dentistry, Department of Oral and Maxillofacial Surgery, Istanbul Gelisim University, Istanbul, Turkey

2 Faculty of Dentistry, Department of Prosthodontics, Biruni University, Istanbul, Turkey

3 Faculty of Medicine, Department of Medical Microbiology, Istanbul Atlas University, Istanbul, Turkey

4 Faculty of Medicine, Department of Medical Microbiology, Kırklareli University, Kırklareli, Turkey

5 Faculty of Dentistry, Department of Oral and Maxillofacial Surgery, Istanbul Atlas University, Istanbul, Turkey

6 Faculty of Dentistry, Department of Pediatric Dentistry, Istanbul Gelisim University, Istanbul, Turkey

7 Faculty of Dentistry, Department of Oral and Maxillofacial Radiology, Beykent University, Istanbul, Turkey
Oral candidiasis is a very complex fungal disease involving oral mucosa which contains different candida species in its structure. Although oral candidiasis is dominated by Candida albicans, C. tropicalis, C. glabrata and C. krusei which are resistant candida species that can be seen in the oral region may also contribute to disease process [1]. In addition, suppression of the immune system, some local and systemic factors may trigger this disease, too. These factors include disorders of saliva content and amount, all-day use of dental prostheses, metabolic diseases, malnutrition, smoking, inadequate oral hygiene, immunosuppressive drug use, chemotherapy and radiotherapy of maxillofacial region [2].

Oral candidiasis is an opportunistic infection affecting the palatal and jugal mucosal regions of the oral mucosa [3]. In addition, the use of nystatin, miconazole, fluconazole and ketoconazole are often recommended for the treatment of this disease [4]. However, the use of these drugs alone may be insufficient to resistant candida species 
[5]. For these reasons, new treatment options are being investigated to increase the treatment efficacy of this disease [6]. Among the new treatment methods, natural product and the efficacy of the bioactive constituent in these products against candida species have been investigated frequently [7].

Nystatin is an active pollen macrolide membrane produced using Streptomyces noursei strains and is produced in different forms such as oral suspension, topical cream and pastil [8]. Nystatin is one of the most commonly used topical antifungal agents in oral candidiasis because it does not show absorption by the gastrointestinal tract when administered orally and its systemic effect is minimal [9]. In addition, besides of its cost-effectiveness nystatin plays an important role in the prophylaxis of oral and systemic candidiasis in infants, elder and immunocompromised patients $[10,11]$. Especially for these patient groups, new combined treatment options should be developed due to the high rates of nystatin resistance observed in Candida spp. in recent studies [12].

Nigella sativa is a $20-30 \mathrm{~cm}$ long flowering plant that grows in the South West, Asia, Europe and North Africa in the Ranunculaceae family and its seeds are commonly known as black seeds or black cumin [13]. A variety of pharmacologically active chemical components have been isolated from the essential oils of black seed; besides thymoquinone, dithymoquinone, thymohydroquinone and thymol; $p$-simene, d-limonene, $\alpha$ and $\beta$-pinene, trans-anethole, carvacrol and nigellone [14].

The quinine components, especially thymoquinone, are responsible for many of the pharmacological effects of black seed [15]. Thymoquinone (2-methyl-5-isopropyl-1,-benzoquinone, TQ) has been used to treat many disease such as rheumatic disease, lung disordes and hypertension [16]. It has been reported that TQ has antifungal activity in addition to its antihistaminic, hypoglycemic, antibacterial, antihypertensive, anti-inflammatory and immune-enhancing effects [17].

The aim of this study was to reveal individual and combinational antifungal effects of TQ and nystatin against $C$. albicans, C. tropicalis, C. glabrata and C. krusei species and to develop an alternative treatment option for resistant oral candidiasis.

\section{Materials and methods}

\section{Bioactive substances}

Thymoquinone (2-isopropyl-5-methyl-1,4-benzoquinone) (Sigma) and nystatin (Sigma) were used in vitro to test the antifungal activity of Candida strains.

\section{Fungal strains}

Candida albicans American Type Culture Collection (ATCC) 10,231, C. tropicalis ATCC 750, C. krusei ATCC 6258 and C. glabrata ATCC 2001 strains were used.

\section{Antifungal broth test}

Antifungal activity of thymoquinone and nystatin was studied in microwell plate using microdilution method according to Clinical Laboratory Standards Institute (CLSI) guidelines. The final concentrations of TQ and nystatin which were diluted in Brain Heart Infusion Broth (BHI) medium were $30 \mu \mathrm{g} / \mathrm{mL}, 15 \mu \mathrm{g} / \mathrm{mL}, 7.5 \mu \mathrm{g} / \mathrm{mL}$, $3.75 \mu \mathrm{g} / \mathrm{mL}, 1.875 \mu \mathrm{g} / \mathrm{mL}, 0.938 \mu \mathrm{g} / \mathrm{mL}, 0.469 \mu \mathrm{g} / \mathrm{mL}$, and $0.234 \mu \mathrm{g} / \mathrm{mL}$. Candida albicans ATCC 10,231, C. tropicalis ATCC 750, C.krusei ATCC 6258 and C.glabrata ATCC 2001 strains were diluted in BHI as well according to 0.5 McFarland turbidity standard and $10 \mu \mathrm{L}$ were added to each well. Each plate incubated overnight at $37^{\circ} \mathrm{C}$. Fungal growth in each well was measured at $600 \mathrm{~nm}$ using Epoch spectrophotometer (Biotek, Germany) in accordance with manufacturer instructions. Broth without TQ and nystatin was used as a control in comparisons.

\section{Interaction between TQ and nystatin combinations via broth microdilution method}

The combination interaction of TQ and nystatin was evaluated for Candida albicans ATCC 10,231, C. tropicalis ATCC 750, C. krusei ATCC 6258 and C.glabrata ATCC 2001 on Brain Heart Infusion Broth (BHI) medium. The final concentrations of TQ and nystatin combination in BHI were $30 \mu \mathrm{g} / \mathrm{mL}, 15 \mu \mathrm{g} / \mathrm{mL}, 7.5 \mu \mathrm{g} / \mathrm{mL}, 3.75 \mu \mathrm{g} / \mathrm{mL}$, $1.875 \mu \mathrm{g} / \mathrm{mL}, 0.938 \mu \mathrm{g} / \mathrm{mL}, 0.469 \mu \mathrm{g} / \mathrm{mL}$, and $0.234 \mu \mathrm{g} /$ mL. C. albicans ATCC 10,231, C. tropicalis ATCC 750, C. krusei ATCC 6258 and C. glabrata ATCC 2001 strains were diluted according to $0.5 \mathrm{McFarland}$ turbidity standard and $10 \mu \mathrm{L}$ was added to each well and allowed to overnight incubation at $37^{\circ} \mathrm{C}$. Fungal growth in each well was measured at $600 \mathrm{~nm}$ using Epoch spectrophotometer (Biotek, Germany) in accordance with manufacturer instructions. Values of thymoquinone, nystatin and candida strains in control wells and values obtained from combinations of TQ and nystatin were used to determine fractional inhibitor concentration (FIC). These FIC values and the value of the $\sum$ FIC index were calculated according to the following formulas;

FIC of antibacterial A (TQ) $=$ MIC of antibacterial $\mathrm{A}$ in combination/MIC of antibacterial A alone, 
FIC of antibacterial B (Nystatin) $=$ MIC of antibacterial $\mathrm{B}$ in combination/MIC of antibacterial $\mathrm{B}$ alone.

FIC of antibacterial A + FIC of antibacterial $B=\sum$ FIC index.

The value of the $\sum$ FIC index is then used to determine whether synergism, indifference or antagonism occurred between the antimicrobial agents and it was used to interpret the nature of the interactions: synergism $\leq 0.5$, indifference $>0.5$ to $\leq 4$, antagonism $>4$ according to American Society of Microbiology [18].

\section{Statistical analysis}

All analyzes were performed in the SPSS program (IBM SPSS Statistics 25). Statistical significance was set at $p<0.05$. As the first step in analyzing the data, the normality assumption was checked with the Shapiro Wilk test. The Kruskal Wallis test was used to examine the difference between the means of variables that do not have a normal distribution and have more than two independent groups.
Bonferroni test was applied to determine the group or groups that made the difference.

\section{Results}

\section{Evaluation between TQ doses and candida strains}

When the antifungal effect of TQ was examined in vitro, it was found that $C$. albicans $C$. tropicalis and $C$. krusei minimum inhibitory concentration (MIC) values were $15 \mu \mathrm{g}$ / $\mathrm{mL}$ whereas it was $30 \mu \mathrm{g} / \mathrm{mL}$ for $C$. glabrata. A statistically significant difference was observed between the mean ranks of Candida strains and doses of TQ $(p<0.05)$. According to the results of the experiments, $7.5 \mu \mathrm{g} / \mathrm{mL}$ and above concentrations of thymoquinone were observed to significantly suppress the growth of C.albicans compared to the lower concentrations tested. Also, while $15 \mu \mathrm{g} / \mathrm{mL}$ and higher concentrations of thymoquinone were observed to significantly suppress the growth of C. tropicalis and C.krusei, a
Table 1 Comparison of TQ doses with Candida species

\begin{tabular}{|c|c|c|c|c|c|c|c|c|}
\hline Species & Dose $(\mu \mathrm{g} / \mathrm{mL})$ & Min & Mak & $\bar{X}$ & SS & Mean ranks & $X^{2}$ & $p$ \\
\hline \multirow[t]{7}{*}{ C.albicans ATCC 10,231 } & 30 & 1.00 & 1.00 & 1.0000 & 0.00000 & 16.50 & \multirow[t]{7}{*}{18.529} & \multirow[t]{7}{*}{$0.005^{*}$} \\
\hline & 15 & 1.00 & 1.00 & 1.0000 & 0.00000 & 16.50 & & \\
\hline & 7.5 & 0.86 & 1.02 & 0.9621 & 0.08962 & 18.00 & & \\
\hline & 3.75 & 0.27 & 0.29 & 0.2774 & 0.01050 & 5.00 & & \\
\hline & 1.875 & 0.30 & 0.36 & 0.3333 & 0.03184 & 10.33 & & \\
\hline & 0.938 & 0.29 & 0.33 & 0.3154 & 0.02019 & 8.67 & & \\
\hline & 0.469 & 0.19 & 0.23 & 0.2136 & 0.02279 & 2.00 & & \\
\hline \multirow[t]{7}{*}{ C.tropicalis ATCC 750} & 30 & 1.00 & 1.00 & 1.0000 & 0.00000 & 18.50 & \multirow[t]{7}{*}{19.837} & \multirow[t]{7}{*}{$0.003 *$} \\
\hline & 15 & 1.00 & 1.00 & 1.0000 & 0.00000 & 18.50 & & \\
\hline & 7.5 & 0.91 & 0.94 & 0.9263 & 0.01535 & 14.00 & & \\
\hline & 3.75 & 0.57 & 0.60 & 0.5930 & 0.01570 & 11.00 & & \\
\hline & 1.875 & 0.53 & 0.53 & 0.5298 & 0.00299 & 8.00 & & \\
\hline & 0.938 & 0.00 & 0.00 & 0.0000 & 0.00000 & 3.50 & & \\
\hline & 0.469 & 0.00 & 0.00 & 0.0000 & 0.00000 & 3.50 & & \\
\hline \multirow[t]{7}{*}{ C.krusei ATCC 6258} & 30 & 1.00 & 1.00 & 1.0000 & 0.00000 & 18.50 & \multirow[t]{7}{*}{19.837} & \multirow[t]{7}{*}{$0.003 *$} \\
\hline & 15 & 1.00 & 1.00 & 1.0000 & 0.00000 & 18.50 & & \\
\hline & 7.5 & 0.92 & 0.93 & 0.9263 & 0.00458 & 14.00 & & \\
\hline & 3.75 & 0.57 & 0.61 & 0.5930 & 0.02248 & 11.00 & & \\
\hline & 1.875 & 0.52 & 0.54 & 0.5298 & 0.00734 & 8.00 & & \\
\hline & 0.938 & 0.00 & 0.00 & 0.0000 & 0.00000 & 3.50 & & \\
\hline & 0.469 & 0.00 & 0.00 & 0.0000 & 0.00000 & 3.50 & & \\
\hline \multirow[t]{7}{*}{ C.glabrata ATCC 2001} & 30 & 1.00 & 1.00 & 1.0000 & 0.00000 & 20.00 & \multirow[t]{7}{*}{15.417} & \multirow[t]{7}{*}{$0.017^{*}$} \\
\hline & 15 & 0.78 & 0.80 & 0.7910 & 0.00934 & 17.00 & & \\
\hline & 7.5 & 0.26 & 0.28 & 0.2711 & 0.01290 & 12.67 & & \\
\hline & 3.75 & 0.22 & 0.29 & 0.2512 & 0.03365 & 8.67 & & \\
\hline & 1.875 & 0.23 & 0.24 & 0.2338 & 0.00692 & 4.67 & & \\
\hline & 0.938 & 0.23 & 0.25 & 0.2413 & 0.01160 & 7.00 & & \\
\hline & 0.469 & 0.20 & 0.26 & 0.2338 & 0.03050 & 7.00 & & \\
\hline
\end{tabular}

$* p<0.05$ 
Fig. 1 Dose-effect plots for Thymoquinone $(\mu \mathrm{g} / \mathrm{mL})$
Thymoquinone $(\mu \mathrm{g} / \mathrm{mL})$

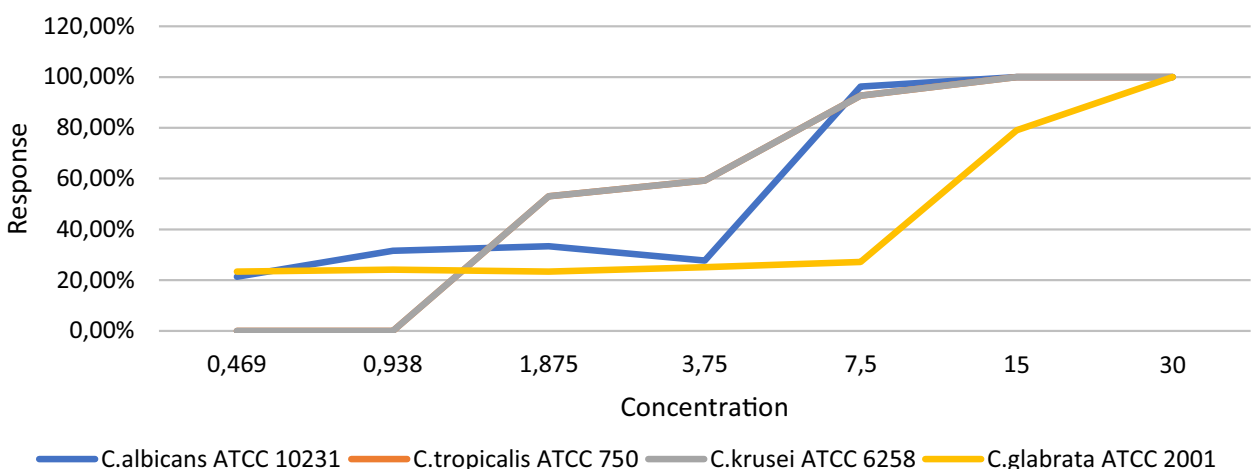

minimum $30 \mu \mathrm{g} / \mathrm{mL}$ thymoquinone needed to inhibit the growth of $C$. glabrata. (Table 1). In addition, dose-effect plots for thymoquinone are shown in Fig. 1.

\section{Evaluation between nystatin doses and candida strains}

MIC for nystatin was calculated as $1.875 \mu \mathrm{g} / \mathrm{mL}$ for $C$. albicans, C. tropicalis and C. krusei, while it was found as $7.5 \mu \mathrm{g} / \mathrm{mL}$ in C. glabrata. A statistically significant difference was observed between the mean ranks of Candida strains and doses of nystatin $(p<0.05)$. Moreover, $1.875 \mu \mathrm{g} /$ $\mathrm{mL}$ and above concentrations of nystatin were observed to be statistically significant in suppressing $C$. albicans, $C$. tropicalis and C. krusei, while concentrations of $7.5 \mu \mathrm{g} /$ $\mathrm{mL}$ and above significantly suppressed the growth of $C$. glabrata compared to the lower concentrations studied. (Table 2). Also dose-effect plots for nystatin are shown in Fig. 2.

\section{Evaluation between combination of TQ-nystatin doses and candida strains}

When the interaction of TQ and nystatin was examined in vitro by microdilution method, it was found that these two substances showed a synergistic antifungal effect at a concentration of $0.234 \mu \mathrm{g} / \mathrm{mL}$ on other strains except $C$. $\mathrm{kru}$ sei, whereas it was $0.117 \mu \mathrm{g} / \mathrm{mL}$ in C. krusei. A statistically significant difference was observed between the mean ranks of Candida strains and doses of TQ-nystatin combination $(p<0.05) .0 .117 \mu \mathrm{g} / \mathrm{mL}$ and above concentrations of the combination of thymoquinone and nystatin were observed to suppress the growth of Candida albicans, $C$. tropicalis and C. glabrata, while concentrations of $0.059 \mu \mathrm{g} / \mathrm{mL}$ and above statistically significantly suppressed the growth of $C$. krusei compared to the lower concentrations studied (Table 3). Furthermore, dose-effect plots for thymoquinone + nystatin is shown in Fig. 3. According to $\sum$ FIC index value, TQ and nystatin was found to have a synergistic effect on all strains (Table 4).

\section{Discussion}

The type and resistance of microorganisms living in oral tissues are critical determinants of health and disease progression [19, 20]. In particular, fungal strains of the candida species are important components for oral microbiota. The activity of these strains varies according to the systemic health and disease status of the individuals [21].

Candida strains can be found in healthy oral mucosa. The incidence of these strains are estimated to be $30-55 \%$ in healthy adults and 45-65\% in healthy infants [22]. The presence of systemic and local factors may promote multiplication of these candida strains which may lead to several diseases in the oral mucosa. These factors include low $\mathrm{pH}$ of oral fluids, decreased salivary flow, continuous use of removable dental prostheses, hormonal disorders, malnutrition, excessive smoking, lack of oral hygiene, immunosuppressive and chemotherapeutic drugs, and radiotherapy from the head and neck [23].

According to human studies, C. albicans is the most common strain in both healthy the mucosa and oral candidiasis, because of its high pathogenicity and ability to adhere to the mucosa [3]. In addition, C. tropicalis, C. krusei and $C$. glabrata strains have been reported to play an important role in oral candidiasis [24]. For these reasons, we included these candida strains in our study.

Currently, various systemic and topical antifungal agents are available for the treatment of oral candidiasis. Triazoles, fluconazole and itraconazole are frequently used systemic antifungal agents in cases of oral candidiasis that do not respond to topical treatment [25]. Drugs such as nystatin, amphotericin B, miconazole and clotrimazole are topical antifungal agents used as initial treatment in patients with oral candidiasis [26]. In 2009, the American Infectious Diseases Association updated clinical practice guidelines for 
Table 2 Comparison of nystatin doses with Candida species

\begin{tabular}{|c|c|c|c|c|c|c|c|c|}
\hline Species & Dose $(\mu \mathrm{g} / \mathrm{mL})$ & Min & Mak & $\bar{X}$ & SS & Mean ranks & $X^{2}$ & $p$ \\
\hline \multirow[t]{7}{*}{ C.albicans ATCC 10,231 } & 30 & 1.00 & 1.00 & 1.0000 & 0.00000 & 14.00 & \multirow[t]{7}{*}{19.347} & \multirow[t]{7}{*}{$0.004 *$} \\
\hline & 15 & 1.00 & 1.00 & 1.0000 & 0.00000 & 14.00 & & \\
\hline & 7.5 & 1.00 & 1.00 & 1.0000 & 0.00000 & 14.00 & & \\
\hline & 3.75 & 1.00 & 1.00 & 1.0000 & 0.00000 & 14.00 & & \\
\hline & 1.875 & 1.00 & 1.00 & 1.0000 & 0.00000 & 14.00 & & \\
\hline & 0.938 & 0.71 & 0.74 & 0.7254 & 0.01637 & 3.00 & & \\
\hline & 0.469 & 0.73 & 0.74 & 0.7346 & 0.00447 & 4.00 & & \\
\hline \multirow[t]{7}{*}{ C.tropicalis ATCC 750} & 30 & 1.00 & 1.00 & 1.0000 & 0.00000 & 14.00 & \multirow[t]{7}{*}{19.837} & \multirow[t]{7}{*}{$0.003 *$} \\
\hline & 15 & 1.00 & 1.00 & 1.0000 & 0.00000 & 14.00 & & \\
\hline & 7.5 & 1.00 & 1.00 & 1.0000 & 0.00000 & 14.00 & & \\
\hline & 3.75 & 1.00 & 1.00 & 1.0000 & 0.00000 & 14.00 & & \\
\hline & 1.875 & 1.00 & 1.00 & 1.0000 & 0.00000 & 14.00 & & \\
\hline & 0.938 & 0.79 & 0.80 & 0.7964 & 0.00638 & 5.00 & & \\
\hline & 0.469 & 0.73 & 0.75 & 0.7385 & 0.00966 & 2.00 & & \\
\hline \multirow[t]{7}{*}{ C.krusei ATCC 6258} & 30 & 1.00 & 1.00 & 1.0000 & 0.00000 & 14.00 & \multirow[t]{7}{*}{19.837} & \multirow[t]{7}{*}{$0.003 *$} \\
\hline & 15 & 1.00 & 1.00 & 1.0000 & 0.00000 & 14.00 & & \\
\hline & 7.5 & 1.00 & 1.00 & 1.0000 & 0.00000 & 14.00 & & \\
\hline & 3.75 & 1.00 & 1.00 & 1.0000 & 0.00000 & 14.00 & & \\
\hline & 1.875 & 1.00 & 1.00 & 1.0000 & 0.00000 & 14.00 & & \\
\hline & 0.938 & 0.52 & 0.55 & 0.5368 & 0.01419 & 2.00 & & \\
\hline & 0.469 & 0.66 & 0.66 & 0.6596 & 0.00358 & 5.00 & & \\
\hline \multirow[t]{7}{*}{ C.glabrata ATCC 2001} & 30 & 1.00 & 1.00 & 1.0000 & 0.00000 & 17.00 & \multirow[t]{7}{*}{19.775} & \multirow[t]{7}{*}{$0.003 *$} \\
\hline & 15 & 1.00 & 1.00 & 1.0000 & 0.00000 & 17.00 & & \\
\hline & 7.5 & 1.00 & 1.00 & 1.0000 & 0.00000 & 17.00 & & \\
\hline & 3.75 & 0.47 & 0.48 & 0.4751 & 0.00632 & 8.00 & & \\
\hline & 1.875 & 0.58 & 0.60 & 0.5896 & 0.01225 & 11.00 & & \\
\hline & 0.938 & 0.23 & 0.27 & 0.2512 & 0.02080 & 2.00 & & \\
\hline & 0.469 & 0.28 & 0.30 & 0.2861 & 0.00937 & 5.00 & & \\
\hline
\end{tabular}

$* p<0.05$
Fig. 2 Dose-effect plots for Nystatin $(\mu \mathrm{g} / \mathrm{mL})$

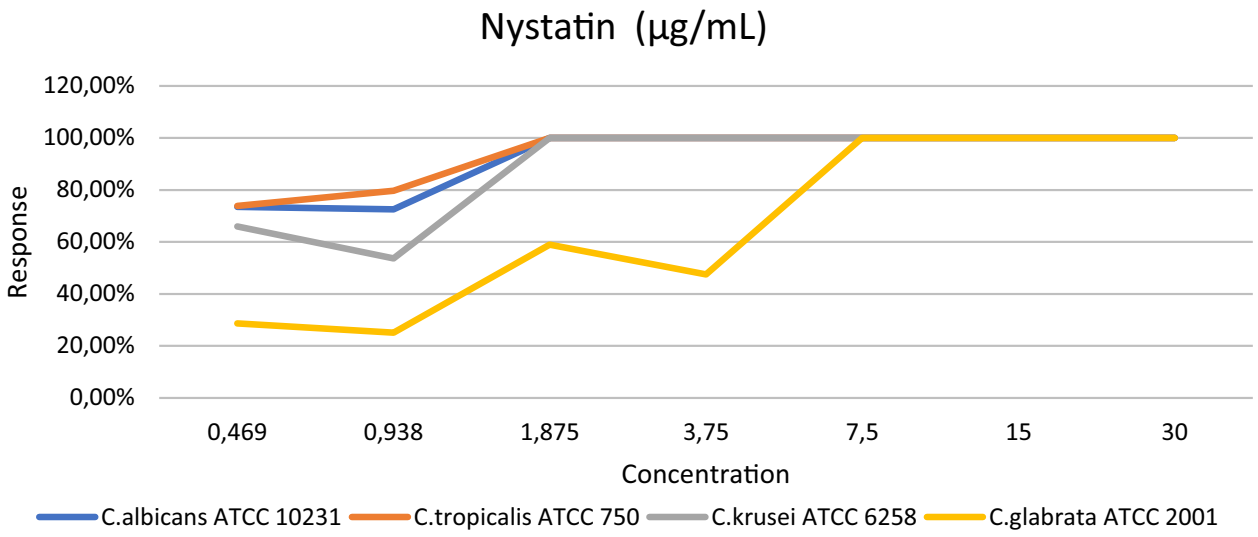

the treatment of mild oropharyngeal candidiasis with a concentration of $100,000 \mathrm{U} / \mathrm{mL}$ of nystatin suspension and 1-2 nystatin pastils (200,000 U each) administered for 7-14 days [27]. In addition, the World Health Organization recommended that topical nystatin use in oropharyngeal candidiasis in HIV-positive patients is an alternative treatment to fluconazole [28]. Nystatin which was used in our study has been reported as an effective treatment of oral candidiasis.

Thymoquinone is the main ingredient of Nigella sativa seed essential oil, which has been proven to have positive effects on many diseases in medical fields as well as in dentistry [29-31]. In many studies, it has been reported that 
Table 3 Comparison of combination TQ-nystatin doses with Candida species
Fig. 3 Dose-effect plots for Thymoquinone + Nystatin $(\mu \mathrm{g} /$ $\mathrm{mL}$ )

\begin{tabular}{|c|c|c|c|c|c|c|c|c|}
\hline Species & Dose $(\mu \mathrm{g} / \mathrm{mL})$ & Min & Mak & $\bar{X}$ & SS & Mean ranks & $X^{2}$ & $p$ \\
\hline \multirow[t]{9}{*}{ C.albicans ATCC 10,231 } & 15 & 1.00 & 1.00 & 1.0000 & .00000 & 17.00 & \multirow[t]{9}{*}{25.880} & \multirow[t]{9}{*}{$0.001^{*}$} \\
\hline & 7.5 & 1.00 & 1.00 & 1.0000 & .00000 & 17.00 & & \\
\hline & 3.75 & 1.00 & 1.00 & 1.0000 & 0.00000 & 17.00 & & \\
\hline & 1.875 & 1.00 & 1.00 & 1.0000 & 0.00000 & 17.00 & & \\
\hline & 0.938 & 1.00 & 1.00 & 1.0000 & 0.00000 & 17.00 & & \\
\hline & 0.469 & 1.00 & 1.00 & 1.0000 & 0.00000 & 17.00 & & \\
\hline & 0.234 & 1.00 & 1.00 & 1.0000 & 0.00000 & 17.00 & & \\
\hline & 0.117 & 0.48 & 0.49 & 0.4874 & 0.00549 & 5.00 & & \\
\hline & 0.059 & 0.18 & 0.19 & 0.1854 & 0.00798 & 2.00 & & \\
\hline \multirow[t]{9}{*}{ C.tropicalis ATCC 750} & 15 & 1.00 & 1.00 & 1.0000 & 0.00000 & 17.00 & \multirow[t]{9}{*}{25.880} & \multirow[t]{9}{*}{$0.001 *$} \\
\hline & 7.5 & 1.00 & 1.00 & 1.0000 & 0.00000 & 17.00 & & \\
\hline & 3.75 & 1.00 & 1.00 & 1.0000 & 0.00000 & 17.00 & & \\
\hline & 1.875 & 1.00 & 1.00 & 1.0000 & 0.00000 & 17.00 & & \\
\hline & 0.938 & 1.00 & 1.00 & 1.0000 & 0.00000 & 17.00 & & \\
\hline & 0.469 & 1.00 & 1.00 & 1.0000 & 0.00000 & 17.00 & & \\
\hline & 0.234 & 1.00 & 1.00 & 1.0000 & 0.00000 & 17.00 & & \\
\hline & 0.117 & 0.51 & 0.52 & 0.5130 & 0.00325 & 5.00 & & \\
\hline & 0.059 & 0.47 & 0.48 & 0.4770 & 0.00507 & 2.00 & & \\
\hline \multirow[t]{9}{*}{ C.krusei ATCC 6258} & 15 & 1.00 & 1.00 & 1.0000 & 0.00000 & 15.50 & \multirow[t]{9}{*}{25.893} & \multirow[t]{9}{*}{$0.001 *$} \\
\hline & 7.5 & 1.00 & 1.00 & 1.0000 & 0.00000 & 15.50 & & \\
\hline & 3.75 & 1.00 & 1.00 & 1.0000 & 0.00000 & 15.50 & & \\
\hline & 1.875 & 1.00 & 1.00 & 1.0000 & 0.00000 & 15.50 & & \\
\hline & 0.938 & 1.00 & 1.00 & 1.0000 & 0.00000 & 15.50 & & \\
\hline & 0.469 & 1.00 & 1.00 & 1.0000 & 0.00000 & 15.50 & & \\
\hline & 0.234 & 1.00 & 1.00 & 1.0000 & 0.00000 & 15.50 & & \\
\hline & 0.117 & 1.00 & 1.00 & 1.0000 & 0.00000 & 15.50 & & \\
\hline & 0.059 & 0.82 & 0.82 & 0.8209 & 0.00193 & 2.00 & & \\
\hline \multirow[t]{9}{*}{ C.glabrata ATCC 2001} & 15 & 1.00 & 1.00 & 1.0000 & 0.00000 & 17.00 & \multirow[t]{9}{*}{25.880} & \multirow[t]{9}{*}{$0.001^{*}$} \\
\hline & 7.5 & 1.00 & 1.00 & 1.0000 & 0.00000 & 17.00 & & \\
\hline & 3.75 & 1.00 & 1.00 & 1.0000 & 0.00000 & 17.00 & & \\
\hline & 1.875 & 1.00 & 1.00 & 1.0000 & 0.00000 & 17.00 & & \\
\hline & 0.938 & 1.00 & 1.00 & 1.0000 & 0.00000 & 17.00 & & \\
\hline & 0.469 & 1.00 & 1.00 & 1.0000 & 0.00000 & 17.00 & & \\
\hline & 0.234 & 1.00 & 1.00 & 1.0000 & 0.00000 & 17.00 & & \\
\hline & 0.117 & 0.79 & 0.80 & 0.7963 & 0.00707 & 5.00 & & \\
\hline & 0.059 & 0.69 & 0.69 & 0.6891 & 0.00101 & 2.00 & & \\
\hline
\end{tabular}

$* p<0.05$

Thymoquinone + Nystatin $(\mu \mathrm{g} / \mathrm{mL})$

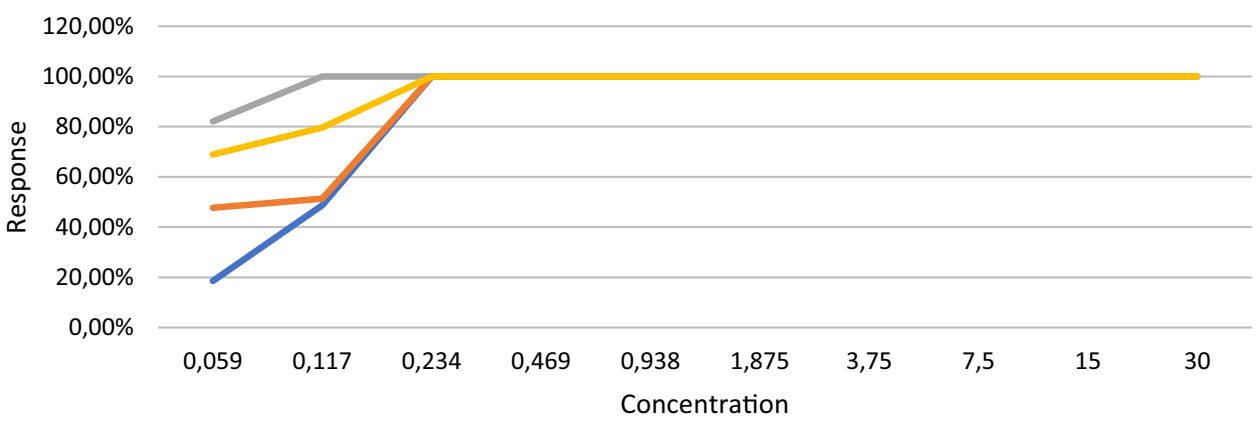

C.albicans ATCC $10231-$ C.tropicalis ATCC $750-$ C.krusei ATCC $6258 \longrightarrow$ C.glabrata ATCC 2001 
Table 4 The MIC of thymoquinone and nystatin combination against Candida strains, and their combined FIC index values

\begin{tabular}{|c|c|c|c|c|c|c|c|c|c|c|}
\hline Thymoquinone + Nystatin $(\mu \mathrm{g} / \mathrm{mL})$ & $\sum$ FIC & 15 & 7.5 & 3.75 & 1.875 & 0.938 & 0.469 & 0.234 & 0.117 & 0.059 \\
\hline C.albicans ATCC 10,231 & 0.141 & $100.00 \%$ & $100.00 \%$ & $100.00 \%$ & $100.00 \%$ & $100.00 \%$ & $100.00 \%$ & $100.00 \%$ & $48.74 \%$ & $18.54 \%$ \\
\hline C.tropicalis ATCC 750 & 0.141 & $100.00 \%$ & $100.00 \%$ & $100.00 \%$ & $100.00 \%$ & $100.00 \%$ & $100.00 \%$ & $100.00 \%$ & $51.30 \%$ & $47.70 \%$ \\
\hline C.krusei ATCC 6258 & 0.07 & $100.00 \%$ & $100.00 \%$ & $100.00 \%$ & $100.00 \%$ & $100.00 \%$ & $100.00 \%$ & $100.00 \%$ & $100.00 \%$ & $82.09 \%$ \\
\hline C.glabrata ATCC 2001 & 0.242 & $100.00 \%$ & $100.00 \%$ & $100.00 \%$ & $100.00 \%$ & $100.00 \%$ & $100.00 \%$ & $100.00 \%$ & $79.63 \%$ & $68.91 \%$ \\
\hline
\end{tabular}

the active substances in the content of Nigella sativa have significant effects on neurological, cardiovascular, respiratory diseases and infertility as well as antimicrobial, antitumoral, antidiabetic, antihyperlipidemic, hepatoprotective and gastrointestinal protective effects. In addition, it has been stated that Nigella sativa ingredients are reliable products in toxicological studies and have no clinically serious side effects [32]. Furthermore, Ulaşli et al. [33], in their study on the coronavirus, which is the cause of the current pandemic, reported that treatment with Nigella sativa extracts before coronavirus infection reduced virus replication within cells. In a dentistry study by Omer et al. [34] in the field of pedodontics, they observed less inflammation and less degenerative changes in the pulp tissue compared to formocresol medicament when they covered the pulp with $N$. sativa oil. In another study, the therapeutic effect of TQ on chronic periodontitis was investigated. At the end of the treatment, patients who were treated with TQ decreased bleeding in the probing, decreased plaque index, a significant decrease in periodontal pocket depth, and increased clinical attachment [31]. In addition, many studies have reported that TQ has antifungal effect. Piras et al. [35] explained that N. sativa extracts have antifungal effect against $C$. albicans, $C$. tropicalis and $C$. krusei compared with fluconazole and ketoconazole in their study. In another study, Khan et al. [36] reported that TQ had a considerable antifungal effect in both fluconazole-sensitive and fluconazole-resistant strains in $C$. albicans-infected mice. In our study, when the antifungal effect of TQ was examined in vitro, C. albicans $C$. tropicalis and $C$. krusei MIC values were found to be $15 \mu \mathrm{g} / \mathrm{mL}$ and $30 \mu \mathrm{g} / \mathrm{mL}$ for $C$. glabrata.

Therapeutic approaches for resistant microorganisms are being developed using many bioactive substances of natural or synthetic origin with therapeutic potential in new drug design or in combinations. Synergistic effects of antifungal agents are realized by some mechanisms. One of these mechanisms is the inhibition of the intracellular mechanisms necessary for the survival of fungal cells. Other mechanisms are to increase penetration caused by another antifungal agent acting on the fungal cell wall and the inhibition seen with different target cells [37]. Castro et al. [2] were reported that thymol and nystatin had a synergistic effect on candida strains. In addition, they expressed that this mechanism of synergistic action is to inhibit the formation of ergosterol which is necessary for the maintenance of the fungal cell by increasing the cell permeability of one or more antifungal agents. In our study, the synergistic antifungal effect in the combined use of nystatin and TQ had a MIC of $0.234 \mu \mathrm{g} / \mathrm{mL}$ in C. albicans, C. tropicalis and C. glabrata, and $0.117 \mu \mathrm{g} / \mathrm{mL}$ in $C$. krusei. We think that the synergistic antifungal mechanism of action we obtained may be the same because the chemical structure of TQ used in our study is similar to that of tymol. In a study similar to our study, Ning et al. reported that antifungal agents had a synergistic effect against candida species with epigallocatechin gallate, a polyphenol found in green tea, and could reduce the side effects using smaller amounts of antifungal medication [38]. Liu et al. [39] reported that glabridin and its synergism with fluconazole have an antifungal effect against candida species. The synergistic mechanisms of these bioactive substances, which have a synergistic effect against candida species seen in our and other studies, may be similar due to their chemical structure consisting of carbon, hydrogen and oxygen atoms.

Due to the synergistic interaction of TQ and nystatin that we found in our study, the dosage of antifungal drugs and their side effects used in the therapy of oral candidiasis could be reduced. We believe that natural bioactive substances with therapeutic potential, such as TQ, will be beneficial in new drug designs as they have less toxic effects than synthetic chemicals. In our opinion, our study will guide the production of new antifungal drugs.

Acknowledgements Statistical analysis was carried out by statistician Ayça Ölmez.

Funding This research received no specific grant from any funding agency in the public, commercial, or not-for-profit sectors.

\section{Declarations}

Conflict of interest All of the authors have stated explicitly that there are no conflicts of interest in connection with this article.

Consent for publication The manuscript has not already been published, accepted or under simultaneous review for publication elsewhere. 


\section{References}

1. Coutinho HDM. Factors influencing the virulence of Candida Spp. W Indian Med J. 2009;58(2):160-3.

2. de Castro RD, de Souza TM, Bezerra LM, Ferreira GL, Costa EM, Cavalcanti AL. Antifungal activity and mode of action of thymol and its synergism with nystatin against Candida species involved with infections in the oral cavity: an in vitro study. BMC Complement Altern Med. 2015;15:417.

3. Mangueira DFB, Mangueira LFB, Diniz MFFM. Candidose oral. R bras ci Saúde. 2010;14(2):69-72.

4. Capistrano HM, Assis EM, Leal RM, Alvarez-Leite ME, Brener S, Bastos EM. Brazilian Green própolis compared to miconazole gel in the treatment of Candida-associated denture stomatitis. Evid Based Complement Alternat Med. 2013;2013:947980.

5. Bondaryk M, Kurzatkowski W, Staniszewska M. Antifungal agents commonly used in the superficial and mucosal candidiasis treatment: mode of action and resistance development. Postępy Dermatol Alergol. 2013;30(5):293-301.

6. Kamikawa Y, Mori Y, Nagayama T, Fujisaki J, Hirabayashi D, Sakamoto R, et al. Frequency of clinically isolated strains of oral Candida species at Kagoshima University Hospital, Japan, and their susceptibility to antifungal drugs in 2006-2007 and 2012-2013. BMC Oral Health. 2014;14:14.

7. Freires IA, Furletti VF, Sartoratto A, Alencar SM, Figueira GM, Murata RM, et al. Coriandrum sativum L. (coriander) essential oil: antifungal activity and mode of action on Candida spp., and molecular targets affected in human whole-genome expression. PLoS ONE. 2014;9(6):e99086.

8. Wong SSW, Samaranayake LP, Seneviratne CJ. In pursuit of the ideal antifungal agent for Candida infections: high-throughput screening of small molecules. Drug Discov Today. 2014;19(11):1721-30.

9. Samaranayake LP, Keung Leung W, Jin L. Oral mucosal fungal infections. Periodontol. 2000;2009(49):39-59.

10. Sklenar Z, Scigel V, Horackova K, Slanar O. Compounded preparations with nystatin for oral and oromucosal administration. Acta Pol Pharm. 2013;70(4):759-62.

11. Gotzsche PC, Johansen HK. Nystatin prophylaxis and treatment in severely immunodepressed patients. Cochrane Database Syst Rev. 2002;4:CD002033.

12. Jabalameli Z, Sabzghabaee A, Mohaghegh M, Maherolnaghsh M, Safavizadeh H, Dehghan P. Antifungal susceptibility of candida species 1solated from cancer patients with oral lesions undergoing chemotherapy. Int J Infect. 2017;4:e14178.

13. Forouzanfar F, Bazzaz BS, Hosseinzadeh H. Black cumin (Nigella sativa) and its constituent (thymoquinone): a review on antimicrobial effects. Iran J Basic Med Sci. 2014;17(12):929-38.

14. Shafiq H, Ahmad A, Masud T, Kalem M. Cardio-protective and anti-cancer therapeutic potential of Nigella sativa. Iran J Basic Med Sci. 2014;17(12):967-79.

15. Darakhshan S, Bidmeshki Pour A, Hosseinzadeh Colagar A, Sisakhtnezhad S. Thymoquinone and its therapeutic potentials. Pharmacol Res. 2015;95-96:138-58.

16. Kara MI, Erciyas K, Altan AB, Ozkut M, Ay S, Inan S. Thymoquinone accelerates new bone formation in the rapid maxillary expansion procedure. Arch Oral Biol. 2012;57(4):357-63.

17. Mahmoudvand H, Sepahvand A, Jahanbakhsh S, Ezatpour B, Ayatollahi Mousavi SA. Evaluation of antifungal activities of the essential oil and various extracts of Nigella sativa and its main component, thymoquinone against pathogenic dermatophyte strains. J Mycol Med. 2014;24(4):e155-61.

18. Botelho MG. Fractional inhibitory concentration index of combinations of antibacterial agents against cariogenic organisms. J Dent. 2000;28(8):565-70.

19. Jenkinson HF, Lamont RJ. Oral microbial communities in sickness and in health. Trends Microbiol. 2005;13(12):589-95.
20. Avila M, Ojcius DM, Yilmaz O. The oral microbiota: living with a permanent guest. DNA Cell Biol. 2009;28(8):405-11.

21. Aas JA, Barbuto SM, Alpagot T, Olsen I, Dewhirst FE, Paster BJ. Subgingival plaque microbiota in HIV positive patients. J Clin Periodontol. 2007;34(3):189-95.

22. Millsop JW, Fazel N. Oral candidiasis. Clin Dermatol. 2016;34(4):487-94.

23. Dangi YS, Soni ML, Namdeo KP. Oral candidiasis: a review. Int J Pharm Pharm Sci. 2010;2(4):36-41.

24. Pfaller M, Neofytos D, Diekema D, Azie N, Meier-Kriesche HU, Quan SP, et al. Epidemiology and outcomes of candidemia in 3648 patients: data from the prospective antifungal therapy (PATH Alliance ${ }^{\circledR)}$ registry, 2004-2008. Diagn Microbiol Infect Dis. 2012;74(4):323-31.

25. Epstein JB, Polsky B. Oropharyngeal candidiasis: a review of its clinical spectrum and current therapies. Clin Ther. 1998;20(1):40-57.

26. Akpan A, Morgan R. Oral candidiasis. Postgrad Med J. 2002;78(922):455-9.

27. Pappas PG, Kauffman CA, Andes D, Benjamin DK, Calandra TF, Edwards JE, et al. Clinical practice guidelines for the management of candidiasis: 2009 update by the Infectious Diseases Society of America. Clin Infect Dis. 2009;48(5):503-35.

28. WHO Guidelines Approved by the Guidelines Review Committee. Guidelines on the Treatment of Skin and Oral HIV-Associated Conditions in Children and Adults. Geneva: World Health Organization. Copyright (c) World Health Organization 2014; 2014.

29. Kundu J, Kim DH, Kundu JK, Chun KS. Thymoquinone induces heme oxygenase- 1 expression in HaCaT cells via Nrf2/ARE activation: Akt and AMPKalpha as upstream targets. Food Chem Toxicol. 2014;65:18-26.

30. Alhebshi AH, Gotoh M, Suzuki I. Thymoquinone protects cultured rat primary neurons against amyloid beta-induced neurotoxicity. Biochem Biophys Res Commun. 2013;433(4):362-7.

31. Al-Bayaty F, Kamaruddin A, Ismail M, Abdulla M. Formulation and evaluation of a new biodegradable periodontal chip containing thymoquinone in a chitosan base for the management of chronic periodontitis. J Nanomater. 2013;3:397308.

32. Gholamnezhad Z, Havakhah S, Boskabady MH. Preclinical and clinical effects of Nigella sativa and its constituent, thymoquinone: a review. J Ethnopharmacol. 2016;190:372-86.

33. Ahmad A, Rehman MU, Ahmad P, Alkharfy KM. Covid-19 and thymoquinone: connecting the dots. Phytother Res. 2020. https:// doi.org/10.1002/ptr.6793.

34. Omar OM, Khattab NM, Khater DS. Nigella sativa oil as a pulp medicament for pulpotomized teeth: a histopathological evaluation. J Clin Pediatr Dent. 2012;36(4):335-42.

35. Piras A, Rosa A, Marongiu B, Porcedda S, Falconieri D, Dessì MA, et al. Chemical composition and in vitro bioactivity of the volatile and fixed oils of Nigella sativa L. extracted by supercritical carbon dioxide. Ind Crops Prod. 2013;46:317-23.

36. Khan MA, Aljarbou AN, Khan A, Younus H. Liposomal thymoquinone effectively combats fluconazole-resistant Candida albicans in a murine model. Int J Biol Macromol. 2015;76:203-8.

37. Johnson MD, Macdougall C, Ostrosky-Zeichner L, Perfect JR, Rex JH. Combination antifungal therapy. J Antimicrob Chemother. 2004;48(3):693-715.

38. Ning Y, Ling J, Wu CD. Synergistic effects of tea catechin epigallocatechin gallate and antimycotics against oral Candida species. Arch Oral Biol. 2015;60(10):1565-70.

39. Lu M, Li T, Wan J, Li X, Yuan L, Sun S. Antifungal effects of phytocompounds on Candida species alone and in combination with fluconazole. Int J Antimicrob Agents. 2017;49(2):125-36.

Publisher's Note Springer Nature remains neutral with regard to jurisdictional claims in published maps and institutional affiliations. 